\title{
SITAC : Social IT Awareness Campaign A Case Study of Computer Awareness Campaign in primary and secondary Schools
}

\author{
Nikhil D. Boob ${ }^{1}$, Prem S. Potabatti ${ }^{2}$, Prof. Anil Surve ${ }^{3}$ \\ ${ }^{1}$ Department of Computer Science and Engineering, ${ }^{2}$ Mechanical Engineering, ${ }^{3}$ Computer Science and Engineering \\ ${ }^{1,2,3,4}$ Walchand College of Engineering, Sangli MH, India \\ nikhilboob@gmail.com¹,prempotabatti@gmail.com²,anil.surve@walchandsangli.ac.in ${ }^{3}$
}

\begin{abstract}
In the present digital era, the development in various aspects of computer technology has reached beyond our imagination and expectations. The application of computers in various sectors of daily life has become inevitable to one extent or other. Therefore, for any country to develop and walk hand in hand with developing countries, it is imperative that at least basic computer education be imparted. Currently, initiatives like MS-CIT and others are proving to be efficient in educating youth. But the computer literacy at primary and secondary schools, especially in rural areas stays minimal. Hence, for any country to develop, it is necessary that the population at even ground level must be educated. Hence, various efforts are put up by government as well as non governmental agencies and voluntary organizations as well in this direction.
\end{abstract}

In this paper, we discuss a model wherein a group of undergraduate students of Walchand College of Engineering, Sangli under the Association of Computer Science Engineering Students (ACSES) put up efforts in this direction through a program called Social IT Awareness Campaign (SITAC).

Nikhil D. Boob

Department of Computer Science and Engineering, Walchand College of Engineering, Sangli MH, India nikhilboob@gmail.com
Students through SITAC visit various rural and village schools and take weekly sessions regarding computer awareness.

Keywords-E-learning, computer technology, awareness, digital era, SITAC

\section{Introduction}

IT and technology plays a dominant role for societal transformation if we want to envision an empowered India. Therefore, realizing the compelling need for Computer literacy in rural as well as urban society, Association of Computer Science Engineering Students (ASCES) has been taking efforts for awaking the students of schools especially of 5th -10 th standard where they can explore opportunities in this field and generate interest in the same.

\section{Current Condiations}

In present scenario, condition of rural education is still inadequate. In some villages, there are very few public schools; children have to travel far away distances to avail these facilities and most schools in these locations do not provide computer education.

A. Problems Faced in Rural Education in India

口 The income of teachers working in the rural area schools are quite low so there is a possibility that teachers give less attention to children.

口 Most of the schools do not have proper infrastructure, so they do not get the opportunity to 
utilize tools required for computer education, sports education and extra-curricular activities.

口 The current transportation systems in these rural areas are quite inadequate so children don't like to travel miles to come to school.

口 There is no excess to supplemental education.

\section{B. Infrastructure Facilities}

Infrastructure facilities are one of the important factors for the implementation of ICT programme in rural areas. Existing Infrastructure in schools needs to be improved for the successful and unhindered implementation of ICT. Without proper infrastructure facilities like power, place of the centre, connectivity and computer related materials and human support the programme will not success. So before start the ICT education programme should make sure all these facilities.

\section{Community Participation}

Involvement/ interest of rural students are one of the significant aspects of computer literacy campaign. Majority of the rural students think computer based education is like computer training in various levels like MS word application and $\mathrm{C}, \mathrm{C}++$ programming and also one of instruments for playing games, need more English knowledge, difficult to access and getting information. So these kinds of the unnecessary taboo should be removed from their mind with help of computer graduate, who are living in rural areas and understand rural student's educational and life condition. Without knowledge about rural condition, working for development of rural education will not give sustainable success to such campaigns.

Due to various developmental activities in education, there are many initiatives taken by the government, but they are not implemented in the schools, so the present scenario remains the same.

\section{Initiatives Taken by Acses, Walchand College of Engg,sangli : Sitac}

ACSES believes that 'A little push in the right direction can make a big difference!'. Through SITAC, ACSES is taking initiative to give this push to children who cannot get proper guidance. It also realizes that IT and technology plays a dominant role for societal transformation if one wants to envision an empowered India. Hence ACSES is taking efforts to spread this awareness.

Today's world is fully indulged in IT technologies but still we have many villages where this root of computer technology has not reached yet. So as a part of social responsibilities and awareness towards society, we ACSES members of WCE, Sangli have taken this initiative to explore the world of computer knowledge. So basic vision of SITAC includes

प IT Awareness

口 Interest Generation in students

口 Encouragement and Motivation

૫ Exploring the Opportunities in Computer field

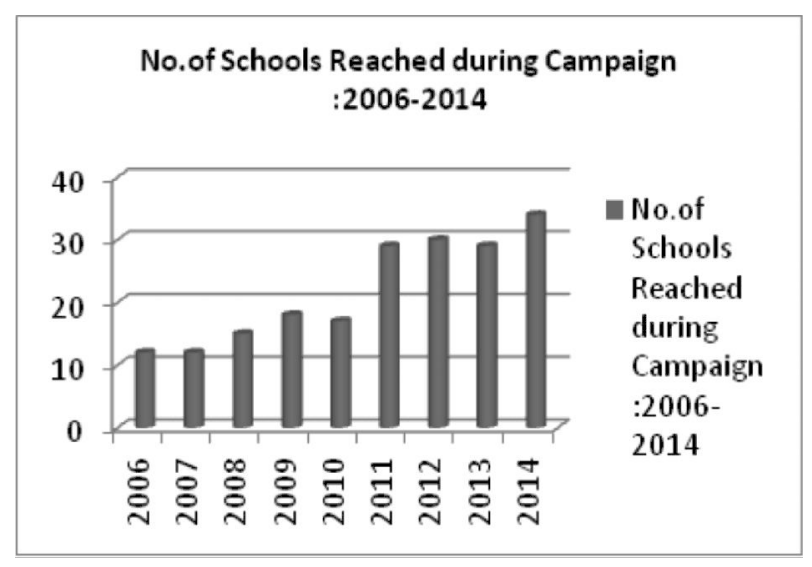

Fig. 1: No. of Schools Reached during Campaigns

Undergraduate computer science students of WCE , design the contents to be delivered to rural schools, and then working in pairs or groups, visit different schools in nearby villages and aware the students and teachers about computer fundamentals, use of internet, e- learning through interactive sessions with the help of devices like laptops, DVDs, projectors, tablets like AAKASH. Students, who actually get the opportunity to handle such devices, become curious about use and study of such technology. This aims at providing the necessary hands-on practical teaching and guidance on use of computers for activities like Word Processing using MS-Word, Analysis \& Charting using MS-Excel, Accessing Mails using Outlook Express and searching the internet for useful information, apart from providing introduction to computers and associated terms.

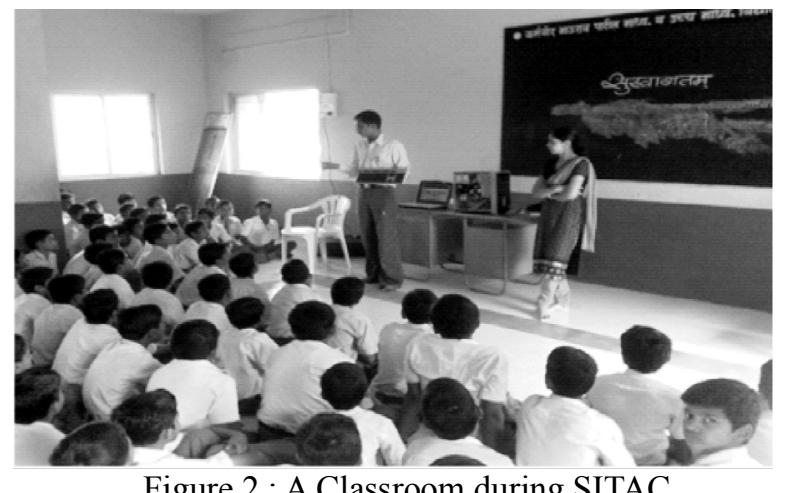

Figure 2: A Classroom during SITAC 


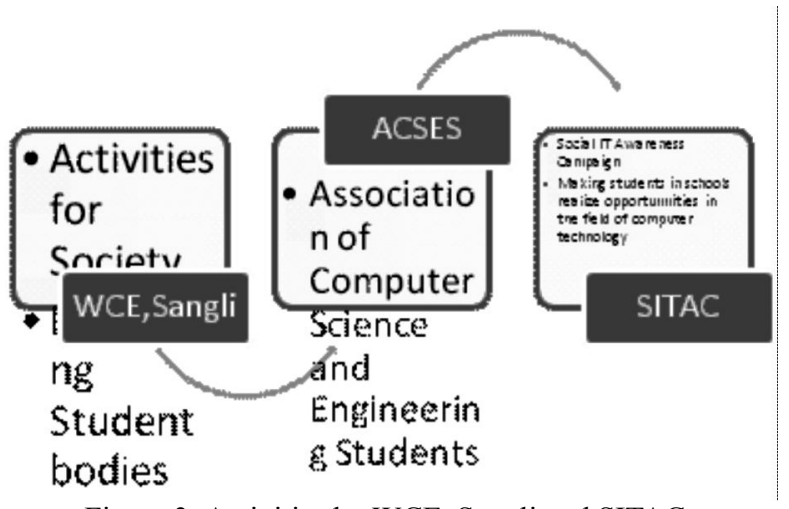

Figure 3: Activities by WCE, Sangli and SITAC

\section{A. Session Covered}

1. Computer Fundamentals

This includes basics of hardware and software of computers along with information regarding mobile devices and robots.

\section{Use of Internet}

Nowadays internet is one of the basic needs of human. In this we include information about basics of internet, server, client, how to use internet, e-mail, search engine etc. Also in some schools, web languages are taught.

\section{Career Guidance}

In this we cover information about various options available after 10th and 12th to make bright future in the various fields of IT.

4. Trends and opportunities in IT \& Computer Industry

This includes information about impacts of IT in our day to day life and enormously growing job opportunities in IT sector.

5. Interactive Quizzes for Students
Quizzes are arranged for students which include basic knowledge of sessions covered and information regarding computer basics and its use.

\section{Feedback Session}

Feedback is taken from both, students as well as teachers of the schools in order to improvise the performance for further sessions.

\section{Acknowledgements}

We are thankful to Staff Advisor, ACSES, Head of Department of Computer Science Engineering, Director and Deputy Director, Walchand College of Engineering, Sangli for their valuable guidance and support for every activity we conduct. We express our gratitude to TEQIP-II for financial support to present this paper.

\section{References}

[1] Information Security Education and Awareness Projecthttp://deity.gov.in/content/informationsecurity-education-and-awareness-project

[2] International Journal of Information and Education Technology http://www.ijiet.org/

[3] M. Ali and D. A. Mission, ?ICT Education Case Study,? Research on Information And Communication Technology, 2003.

[4] Stiemen. Managing Director, IICD. (November 2007). ICT for Development and Education, pp. 16-21, [Online].

[5] Troyer, M.B., (1988) Issues and problems in teacher computer literacy education. Journal of Research on Computing in Education. 7, 25-27. 